\title{
Cryptococcus neoformans causing meningitis in AIDS patients
}

\author{
Meningitecausada pelo Cryptococcus neoformans em pacientes com AIDS \\ Everardo Albuquerque Menezes', Maria Neuman Ricarte Monteiro', \\ Maria Rozelê F. Angelo ${ }^{2}$, Cintia Duarte Santos ${ }^{1}$, Caio César \\ Furtado Freire ${ }^{1}$ and Francisco Afrânio Cunha ${ }^{1}$
}

\begin{abstract}
Cryptococcus neoformans causes meningitis in AIDS patients. In the São José Hospital, reference center for patients with AIDS in Fortaleza - Ceará State - Brazil, 54 samples of the cerebrospinal fluid were analyzed from January $1^{\text {st }}$ through December 31 $31^{\text {st }}$ 2000. Direct examination with India ink and culture in Sabouraud's agar at $37^{\circ} \mathrm{C}$ were done. Of the specimens studied 5(9.25\%) were positive.

Key-words: Cryptococcus neoformans. Meningitis. Cerebrospinal fluid. AIDS.
\end{abstract}

Resumo Cryptococcus neoformans causa meningite em pacientes com AIDS. Foram analisadas 54 amostras de líquido céfalorraquidiano no período de 1 de janeiro a 31 de dezembro de 2000, no Hospital São José, centro de referência para pacientes com AIDS em Fortaleza - Ceará - Brasil. Foram realizados exame direto com tinta da India e cultura em ágar Sabouraud a $37^{\circ} \mathrm{C}$. Entre as amostras estudadas, 5(9,25\%) foram positivas. Palavras-chaves: Cryptococcus neoformans. Meningite. Líquido cefalorraquidiano. AIDS.

Cryptococcosis is an infectious mycosis that begins as a pulmonary infection and spreads in a hematogenous manner to involve the meninges, skin, kidneys, and other organs ${ }^{1}$. Cryptococcus neoformans, the etiologic agent of the disease, is a saprobe in nature, with a worldwide distribution and is especially common in pigeon droppings. While birds are not affected, they apparently harbor the organism in a commensal form. Human infection occurs when dust from soil contaminated with the organism is inhaled. Cryptococcus is rare in persons with an unimpaired immune system. Cryptococcosis is a leading mycological cause of morbidity and mortality among AIDS patients. In many patients, cryptococcosis is the first indication of AIDS. In Brazil Cryptococcus neoformans is the sixth most common opportunistic agent of infection in patients with AIDS, surpassed by Candida species, P. carinii, Mycobacterium species, Toxoplasma gondii, and herpes simplex virus. In northeast region of Brazil there have been few studies regarding cryptococcosis realized until this moment, which explains the lack of knowledge about this disease ${ }^{2}$. Signs and symptoms are referable to meningeal involvement or to increased intracranial pressure: headache at first, then vertigo, dizziness, neck rigidity, amblyopia, and clouding of the sensorium. Central nervous system symptoms are usually the presenting features, while pulmonary involvement may go unnoticed ${ }^{5}$. Untreated cryptococcosis meningitidis is fatal, with very rare exceptions ${ }^{10}$. The association of cryptococcosis with AIDS has a new dimension to descriptive diagnosis. In this setting therapy can achieve suppression of active cryptococcosis disease, but cure is essentially unknown.

The purpose of the research was to verify the occurrence of cryptococcal meningitis in patients with AIDS at São José Hospital, reference center for patients with infectious diseases in Ceará State, Brazil.

\footnotetext{
1.Departamento de Análises Clínicas e Toxicológicas da Universidade Federal do Ceará, Fortaleza, CE. 2. Laboratório Central da Secretaria de Saúde do Ceará, Fortaleza, CE.

Address to: Dr. Everardo Albuquerque Menezes. R. Henriqueta Galeno 1000/701, Dionísio Torres, 60135-420 Fortaleza, CE, Brazil.

Tel: 5585 288-8266.

e-mail:menezes@ufc.br

Recebido para publicação em 19/3/2002.
} 
Patients. Cerebrospinal fluid (CSF) was studied from HIV infected patients with signs and symptoms of meningitis at São José Hospital - Ceará, Brazil.

Samples. A total of 54 samples of cerebrospinal fluid were analyzed from $1^{\text {st }}$ January 2000 through $31^{\text {st }}$ December 2000. They were collected from HIV patients with signs and symptoms of meningitis at São José Hospital - Ceará, Brazil.

Direct examination. Laboratory investigation of cerebrospinal fluid (CSF) is traditionally based on microscopic examination of India ink preparations. The direct examination was first made through India ink diluted at $1: 5^{6}$.

Culture. The cerebrospinal fluid was cultured on Sabouraud's glucose agar and incubated at $37^{\circ} \mathrm{C}$ for five or eight days ${ }^{5}$.

Identification. Two biochemical tests that define C. neoformans, assimilation of inositol and production of urease were performed 6 .

The India ink examination showed capsulated yeast cells in five (9.25\%) samples of cerebrospinal fluid from HIV patients. The centrifuged cerebrospinal fluid contains thick-walled oval or spherical cells, 10 to $15 \mu \mathrm{m}$ in diameter. A thick capsule surrounds these cells. Culture confirmation is required to establish a diagnosis.

Five $(9.25 \%)$ samples of the cerebrospinal fluid presented growth in Sabouraud's glucose agar. The isolated colonies were whitish to brownish, slimy and mucoid.

The confirmation of the Cryptococcus neoformans was done by assimilation of inositol and production of urease. The two tests were positive in five yeasts grown in Sabouraud's glucose agar. It was concluded that five $(9.25 \%)$ of the samples of cerebrospinal fluid contained Cryptococcus neoformans.

Cryptococcal meningitis characteristically occurs in a setting of depressed cell-mediated immunity and is usually associated with AIDS patients ${ }^{4}$. Cryptococcosis is rare in individuals with an unimpaired immune system. Human infection occurs when dust from soil and the environment contaminated with Cryptococcus neoformans is inhaled. Clinical types include infections of the pulmonary system, central nervous system, and other organs ${ }^{3}$. Laboratory investigation of cerebrospinal fluid (CSF) is traditionally based on microscopic examination of India ink preparations, but direct microscopic examination is a rapid but relatively insensitive test that strongly depends on the operator's skills. Moreover, the simple culture of CSF samples on Sabouraud's agar is time-consuming; in fact, at least four days are necessary to detect positive cultures of C. neoformans ${ }^{9}$. In our study, although the fungi were isolated from five AIDS patients with cryptococcal meningitis, we could not determine whether these sites were the real source of the fungal infection, thus in AIDS patients $C$. neoformans usually tends to disseminate, the most common local for extrapulmonary infection being the meninges. The frequency and intensity of human exposure to environmental sources of Cryptococcus neoformans might account for the observed differences in the incidence of cryptococcal meningitis among AIDS patients according to geographical area, since clinical and environmental isolates from different areas have shown similar pathogenicity ${ }^{7}$. Investigations carried out in Central Africa by Passony et $\mathrm{al}^{8}$ showed that AIDS patients with cryptococcosis are frequently exposed to $C$. neoformans in their immediate daily, domestic environment. In New York, the fungus was isolated in $35 \%$ of the AIDS-associated cryptococcosis patients ${ }^{11}$. Divergences in the literature make conclusions difficult, however the prevalence of C. neoformans in domestic environments probably depends on housing conditions, people's habits, and climatic aspects occurring in distinct geographical areas.

C. neoformans is cosmopolitan, which means that the area selected for sampling is not necessarily the area where the patient acquired the infection. Moreover, the time interval between the inhalation of the organism and expression of the disease is not known and some cases might arise from reactivation of a latent focus rather than from exposure to a saprophytic source ${ }^{4}$. Varma et $\mathrm{al}^{12}$ suggest that presence of $C$. neoformans in the domestic environment of HIV-infected individuals might favor their infection or reinfection by the fungus. Consequently, if we consider the possible participation of environmental factors in opportunistic cryptococcosis, it seems prudent to advise HIV-infected individuals of situations that carry a potential risk of acquiring cryptococcosis.

This short study is important to provide physicians with initial information about cryptococcal meningitis in Fortaleza, Ceará, Brazil, which will increase the possibilities of understanding this disease.

\section{REFERENCES}

1. Crissey JT, Lang H, Parish LC. Manual of Medical Mycology. $1^{\text {st }}$ edition. Blackwell Science, New York 1997.

2. Darzé C, Lucena R, Gomes I. Clinical and laboratory characteristics of 104 cryptococcus meningoencephalitis cases. Revista da Sociedade Brasileira de Medicina Tropical 33: 21-26, 2000.

3. Ellis DH, Pfeifer TJ. Natural Habitat of Cryptococcus neoformans. Journal Clinical of Microbiology 28:1642-1644, 1990.
4. Fernandes OFL, Costa TR, Costa MR. Cryptococcus neoformans in patients with AIDS. Revista da Sociedade Brasileira de Medicina Tropical 33: 75-78, 2000.

5. Lacaz CS, Porto E, Martins JEC. Micologia Médica. Sarvier, São Paulo, 1998.

6. Lazera MS, Wanke B, Nishikawa MM. Isolation of both varieties of Cryptococcus neoformans from saprophytic sources in the 
city of Rio de Janeiro, Brazil. Journal Medical Veterinary and Mycology 31: 449-454, 1993.

7. Lortholary O, Improvisi L, Nicolas M, Provost B, Dupont B, Dromer F. Fungemia during murine cryptococcosis sheds some light on pathophysiology. Journal of Medical Veterinary and Mycology 37:169-174, 1999.

8. Passoni LFC, Wanke B, Nishiukawa MM, Lazera MS. Cryptococcus neoformans isolated from human dwellings in Rio de Janeiro, Brazil: an analysis of the domestic environment of AIDS patients with and without cryptococcosis. Journal of Medical Veterinary and Mycology 36: 305-313, 1998.

9. Rappelli P, Are R, Casu G, Fiori PL, Cappuccinelli P, Aceti A. Development of a Nested PCR for Detection of Cryptococcus neoformans in Cerebrospinal Fluid. Journal of Clinical Microbiology 36: 3438-3440, 1998.

10. Rippon JW. Cryptococcosis. In: Medical Mycology. The pathogenic Fungi and the Pathogenic Actinomycetes. $3^{\text {rd }}$ edition. Philadelphia, Saunders p. 582-609, 1988.

11. Sukroongreung S, Kitiniyom K, Nilakul C, Tantimavanich S. Pathogenicity of Cryptococcus neoformans var. neoformans. Journal of Medical Veterinary and Mycology 36: 419-424, 1998.

12. Varma A, Swinne D, Staib F, Bennett JE, Know-Chung KJ. Diversity of DNA fingerprints in Cryptococcus neoformans. Journal of Clinical Microbiology 33: 1807-1814, 1995. 